\title{
An exposition into the changing climate of Bengal Duars through the analysis of more than 100 years' trend and climatic oscillations
}

\author{
Koyel SAM* (D) and NAmita Chakma \\ Department of Geography, The University of Burdwan, Bardhaman, West Bengal, India. \\ *Corresponding author.e-mail: koyelsam04@gmail.com
}

MS received 13 September 2017; revised 20 June 2018; accepted 20 August 2018; published online 11 March 2019

Duars is located along the foothills of the Eastern Himalayas with an assemblage of forest cover. It extends from the river Tista in West Bengal to the river Dhunseri in Assam. Within this broad outline, the areal extension between the rivers Tista and Sankosh covering West Bengal is now known as the Bengal Duars or Western Duars and the rest of the portion that lies in the Assam district is named as the Assam Duars or Eastern Duars. In the present study, multi-decadal variability and trends of climatic events (temperature and extreme rainfall) in the Bengal Duars region have been analysed based on longterm dataset (more than 100 years). This region has experienced an increasing trend of temperature. The results show that the average temperature increases by $0.027^{\circ} \mathrm{C}_{\text {year }}^{-1}$ and extreme rainfall becomes $5 \%$ higher than earlier since 1975.

Keywords. Himalayan foothills; climate change; Bengal Duars; West Bengal.

\section{Introduction}

Climate is defined as the statistics of weather conditions over longer periods of time (minimum 30 or 35 years). The Intergovernmental Panel on Climate Change (IPCC) in its 4th Assessment Report (2007b) stated that climate change as longterm changes in climatic variables (temperature, humidity, clouds and rainfall). Like other physical phenomena, climate is not static, rather it is fairly dynamic in nature. It follows a natural rhythm of change, but the rate and nature of change since pre-industrial era have been accelerated by anthropogenic activities. Recently, the phenomenon of climate change is considered to be of high academic importance and scientists began to recognise the inherent variability of climate on a temporal basis. With an ever-growing awareness among the general public and the governments of the possibility of deterioration of Earth's climate, climate change has been viewed as a great concern for the future of humans on the Earth's surface.

As it is now evident from observations of average air temperature and ocean temperatures, widespread melting of snow and rising global average sea levels, there is no doubt that climate change is a fact and is already taking place, and the warming of the climate system is believed to be unambiguous (Nicholson et al. 2000; Dessai and Hulme 2001; IPCC 2007a). The Earth's average surface temperature had risen by $0.76^{\circ} \mathrm{C}$ since 1850 and most of the warming that has occurred over the last 50 years is likely caused by anthropogenic activities (Somorin 2010). IPCC (2014) in its 5th Assessment Report (AR5) has projected the Representative Concentration Pathways scenario of future global surface temperature, which is likely to rise further by $1.0-3.7$ in this century. Ravindranath et al. 
(2011) in their study on climate change modelling of India show that the Indian subcontinent is likely to experience warming of over $3-5^{\circ} \mathrm{C}$ with a significant change in the flood and drought frequency and intensity. The possible changes in extreme weather events may cause an increase in the frequency of heat waves and drought in the northern Indian region (Sen Roy and Singh 2002).

Through the advancement of climate modelling, the Global Circulation Models (GCMs) of the 21st century are applied by researchers to predict the global future climate scenario considering the broad areal extent with a horizontal resolution between 100 and $300 \mathrm{~km}$ or more (e.g., continents) and also for micro-regions. GCMs often fail to capture the fine-scale structures that affect the regional climate due to their coarse resolution, specifically South Asian monsoon climate (Rajendran et al. 2013). However, there exists large uncertainty in projections of Asian monsoon precipitation (Turner and Slingo 2009). Moreover, different horizons of GCMs predict the future climate in a different manner, thus validation and reliability of GCMs for predicting the local climate are needed for further research. However, it is important to either employ high-resolution models or predict future climate on the basis of historical climatic trends and oscillations.

There are extensive literatures which specifically address the climate change in India with varying spatial and temporal details. One comparative study has been done by Rajendran et al. (2013) to observe and project the Indian summer monsoon rainfall and extreme events at different resolution models. The very high-resolution model shows a relatively heavy occurrence of summer monsoon rainfall during 1979-2003, as well as a spatially varying increasing trend is projected over the IndoGangetic plain and Northeast India. On the other hand, the rainfall pattern is underestimated in the ultra-high-resolution model around the northeastern part of India including West Bengal. Likewise, 104 years' variability and trends of extreme rainfall event have been examined using high-resolution gridded data by Rajeevan et al. (2008). However, Rakhecha and Pisharoty (1996) and Sinha Ray and Srivastava (2000) have studied the station-wise variability of rainfall events of some places in India. Sub-district level trend of rainfall has been assessed by Kaur et al. (2017) in which $10 \%$ of the area of India shows a significant increasing trend and $8 \%$ of the area experienced a decreasing trend of annual rainfall (1901-2013). Laskar et al. (2014) investigated the trending nature of temperature and rainfall over Northeast India, where the rate of change varies from station to station. A study by Radhakrishnan et al. (2017) shows a significant positive trend of temperature and declining rainfall of India in the last 30 years over the period of 1901-2014, and the seasonal variability is also profound in their study.

In the present study, our objective is to analyse the climatic variability of a micro-region (Bengal Duars) to show the long-term climatic change. For this, we analyse seasonal as well as annual climatic variability and trends using high-resolution gridded data to get a clear overview of the previous climate. Further, the influence of climatic anomalies can be seen in the variability and shifting of the seasonal climate of the Duars region. Finally, the trends of future climate are addressed by observing the historical trends.

\section{Is changing climate a non-escaping phenomenon?}

Climate has changed throughout the geological timescales since the inception of Earth. Forcings of past climate change include continental drift, variations in the Earth's orbit around the Sun, changes in solar output, volcanic emissions, cosmic collisions and aerosols in the atmosphere. On timescales of thousands of years, all these act very slowly. Now, we are facing changes in the climatic system due to large-scale emission of greenhouse gases (GHGs) on the timescale of decades. Thus, we are experiencing a similar impact on the natural system, but in a much faster time frame, leading to rapid catastrophic changes in the environment. At the end of the last glaciations, the average global warming occurred at the rate of about $1^{\circ} \mathrm{C}$ or less per thousand years, although there were short periods during which warming was much faster (Pittock 2009).

The observed trends and other indicators of the changing global climatic system have been evaluated in IPCC's 5th Assessment Report. It has been reported that the last three decades were successively warmer than any preceding decade since 1850. The period from 1983 to 2012 was likely to be the warmest 30-year period of the last 1400 years in the Northern Hemisphere. The globally averaged combined land and ocean surface temperature shows a linear trend of warming of $0.85^{\circ} \mathrm{C}$ $\left(0.65-1.06^{\circ} \mathrm{C}\right)$ during the period $1880-2012$ and 
the global mean sea level rose by $0.19 \mathrm{~m}$ during the period 1901-2010. The imprints of humans on the environment can be seen at remarkably early times in our planetary existence, but almost at local and regional levels only. Human activities have recently become so pervasive that their imprints on the environment at the global level are quite obvious. GHG emission in the atmosphere causes temperature increase and associated climate change by anthropogenic activities since the mid-20th century. Overall, human imprints can best be summarised as an increase in 'domesticated land', that is in cropland and pastures, at the expense of forest and other more natural land covers. Since Holocene, the most recent geological period of earth history, humans have developed agriculture, cities, industries and more complex civilisations. The arrival of the Anthropocene causes paradigm shifts in the human-environment relationship at a global level, changing the postulation of automatically continuation of the Earth's system.

According to NASA's Goddard Institute for Space Studies, 2015 was the warmest year since modern record keeping began in 1880 and in this year, for the first time, the global average temperature was recorded as $1^{\circ} \mathrm{C}$ or more above the 1880-1899 average (Peterson and Baringer 2009). Even though the 2000s witnessed a solar output decline resulting in an unusually deep solar minimum in 2007-2009, surface temperatures continue to increase (Allison et al. 2009). Climate has changed and is changing by its natural rhythm, but changing physical (land use and land cover) and chemical compositions (land, air and water pollution) in addition leading to a change in the surface albedo of the Earth.

\section{Duars region: An account of changing climate}

In the literature, Duars is known as 'Doors or Dooars'. As stated in the Rennie's book 'Bhotan and the story of the Dooar War' (1866), Duars is located along the foothills of the Himalayas, extending from the river Tista in Bengal to the river Dhunseri in Assam. 'Duars' means 'door' or 'corridor' between the Bhutan hills and the plains of India. The narrow strip of land, with a breadth of 20-30 miles and length of about 180 miles, assemblages with the forest cover stretching between the river Sankosh in the east and the river Tista in the west, forms the northern boundary of West Bengal and is known as Bengal Duars or Western Duars, and the other parts in Assam district are popularised as Assam Duars or Eastern Duars (Gruning 1911). This region acts like an ecotone of sub-Himalayan physiography and the Brahmaputra plain. The immense beauty of nature with an assemblage of forestry and biodiversity acts like an umbrella on the head of West Bengal. In the colonial period, the numerous and valuable forest cover of the Duars region was converted into tea gardens and reserved forests. The study area, Bengal Duars, extends from $26^{\circ} 30^{\prime}-27^{\circ} 11^{\prime} 20^{\prime \prime} \mathrm{N}$ to $88^{\circ} 25^{\prime} 18^{\prime \prime}-89^{\circ} 52^{\prime} 40^{\prime \prime} \mathrm{E}$ and now it covers a large portion of the Jalpaiguri district, Alipurduar district, part of Darjeeling (before February 2017) and Koch Bihar district (see figures 1 and 2).

The Duars region, owing to its proximity to the hills, experiences rainfall that is much heavier and temperatures that are seldom excessive (Gruning 1911) unlike the southern part of West Bengal and heavy rains have made the climate damp and the area marshy. This region is well known to be unhealthy because it has an evil reputation for malaria and blackwater fever. The most relevant information related to the past climate was found in Dr. Francis Buchanan Hamilton's (1838) book related to accounts of the district of Ronggopoor. It had been reported that the temperature of the Terai and Duars never exceeded $27^{\circ} \mathrm{C}$, and now it increases gradually especially in the summer season, the highest temperature recorded in Jalpaiguri was $40^{\circ} \mathrm{C}$ in 1932 on 11th April (West Bengal District Gazetteers 1981). The region located in the foot of Sikkim and Bhutan Himalayas receives an annual rainfall of $3000 \mathrm{~mm}$. Of this, $1800 \mathrm{~mm}$ of rainfall occurs in the monsoon months only (Jana 2002). Therefore, the trend analysis of extreme rainfall events is important, considering the flood vulnerability of this region.

\section{Data sources and analytical methods}

Daily and monthly climatic data of rainfall (1901-2015) and temperature (1951-2014) were extracted from the gridded $\left(0.25^{\circ} \times 0.25^{\circ}\right.$ and $\left.1^{\circ} \times 1^{\circ}\right)$ dataset of India Meteorological Department (IMD), Pune, and the temperature data (1901-1950) were also collected from this web link http://www.indiawaterportal.org/met_data/. Studies of climate change require a long period 


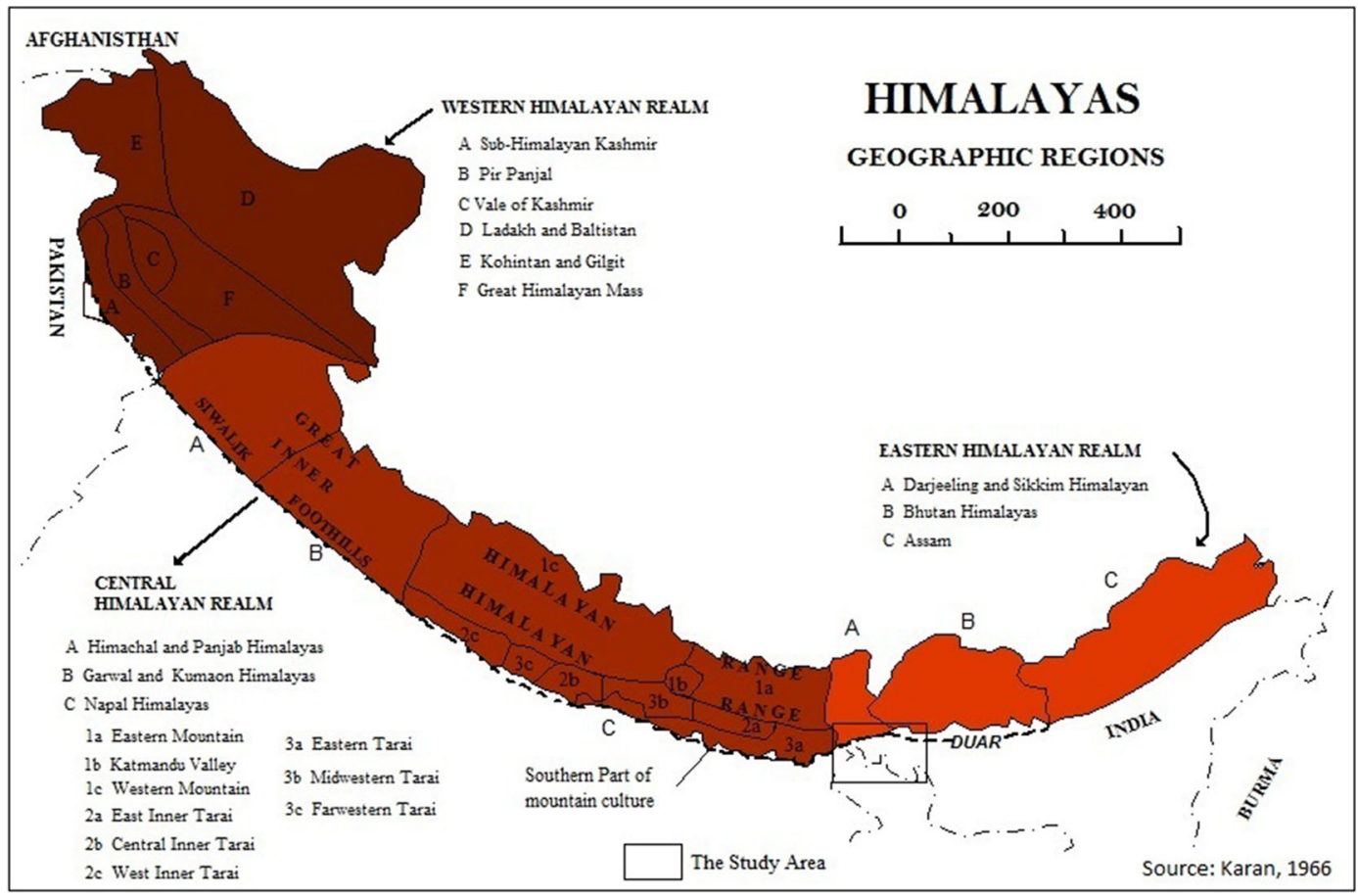

Figure 1. The Himalayan realms. Source: After Karan (1966).

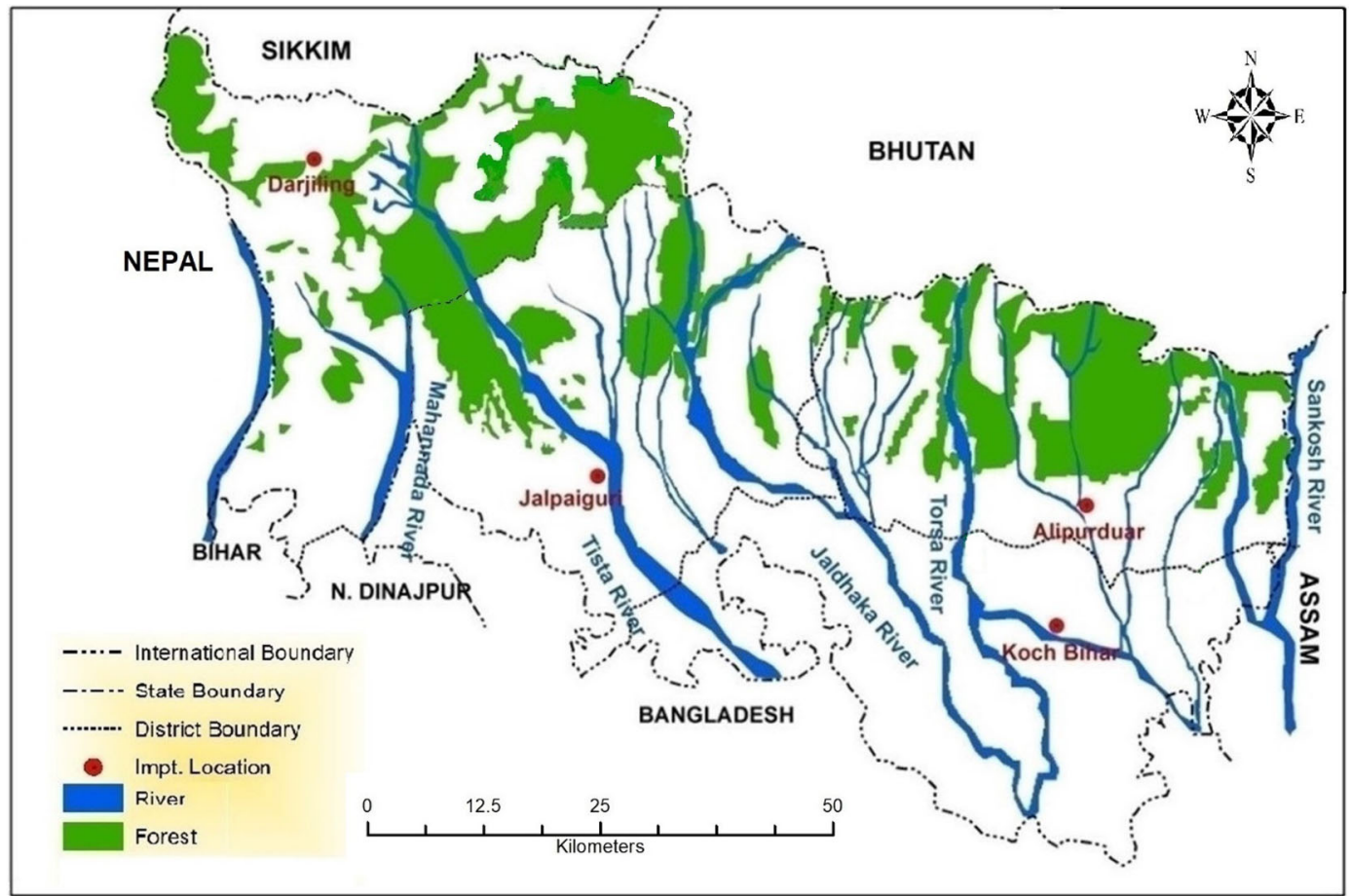

Figure 2. The study area.

of data to identify long-term trends rather than short-term fluctuations (WMO 1996). In this study, more than 100 years' data have been used for the analysis of the climatic variability of the Duars region of West Bengal. In order to evaluate trends, both parametric and non-parametric test statistics have been executed. Further, multi-decadal oscillation of climatic anomalies in extreme events obtained from quantiles between sub-periods of chosen length and the full or reference time series, and box-and-whisker plot have also been used to assess the trends in seasonal climate. 


\subsection{Analysis of climatic trends}

The non-parametric Mann-Kendall trends test is applied to determine whether there exists any trend or not in the data series. It is valid for a sequential dataset of independent and identical distributed values $x_{i}, i=1, n$ under the null hypothesis ( $\mathrm{H} 0$ ) of no trend in the data. The Mann-Kendall test statistics value is computed as

$$
S=\sum_{i=1}^{n-1} \sum_{j=i+1}^{n} \operatorname{sgn}\left(x_{j}-x_{i}\right),
$$

where $\operatorname{sgn}(x)=-1$ for $x<0, \operatorname{sgn}(x)=0$ for $x=0$ and $\operatorname{sgn}(x)=1$ for $x>0$. A positive value indicates an increasing trend and a negative value denotes a decreasing trend.

If the sample size is $\geq 8$, the test statistics $S$ is approximately normal and the variance of $S$ is as follows:

$$
V(S)=\frac{1}{18}[n(n-1)(2 n+5)],
$$

where $n$ denotes the length of the time series and the standardised statistical test $Z$ is computed as

$$
\begin{aligned}
Z & =\frac{S-1}{\sqrt{ } V(S)} \quad \text { if } S>0, \\
& =\frac{S+1}{\sqrt{ } V(S)} \quad \text { if } S<0 .
\end{aligned}
$$

All tests were at $\alpha=0.05$ level. Linear regression is used as a parametric test to analyse the linear trend of climatic events.

\subsection{Analysis of multi-decadal oscillations}

Multi-decadal oscillations and anomalies in climatic events have been analysed based on the works of Ntegeka and Willems (2008) and Willems (2013a, b). In the present study, we have considered 30 years as a sub-period for the analysis of the trends and oscillations in temperature and rainfall of the Bengal Duars region. The extremes are extracted from the full available series and based on subsets of extremes in sub-periods of 15 or 30 years' length. Quantiles in a sub-period are compared with the corresponding quantiles derived from the full series. The relative difference between the sub-period-based quantile and the corresponding full-period-based quantile is computed for all quantiles above a specific threshold. The above values are considered as an 'extreme' and are called as a threshold, which corresponds to a specific frequency of occurrence in time or a specific mean recurrence interval.

\subsection{Test of significance}

To test whether the trends and anomalies identified in the historical series are significant or not, confidence intervals are calculated on the anomalies factors. Under the hypothesis of randomness (no trends or non-persistence), the percentages of anomalies are calculated. When the empirical anomalies go beyond the confidence level, nonpersistence hypothesis (no trends) can be rejected, i.e., it is considered to be statistically significant at a specific confidence interval. Whereas the region inside the confidence bounds is considered to be insignificant (hypothesis accepted). On the other hand, the $95 \%$ confidence intervals are calculated from the whole historical series. For example, 100 random samples (same size as historical series) are generated. For each random sample, anomaly calculation is repeated leading to generate 100 values of each year of historical series. After ranking the 100 values, 25 th and 75 th sample values define the $95 \%$ confidence interval for each particular year.

\section{Results}

\subsection{Trends of temperature and rainfall extremes in Bengal Duars}

Climate changes through the historical periods can be assessed using the statistical trend analysis. It also allows investigation of whether these changes can be considered statistically significant in comparison with the natural temporal variability (as observed in long series). Here, the calculated test statistics values $(S)$ of temperature (6.64) and rainfall extreme (4.32) in the Duars region are greater than the threshold value (1.96) at $5 \%$ levels of significance (see table 1). Therefore, the trends of annual average temperature and extreme rainfall are increasing significantly with an observing trend. The rate of change in average temperature is found to be higher compared to the rate of change in rainfall extremes (see figures 3 and $4 a$ ).

\subsection{Multi-decadal oscillations in temperature and rainfall extremes}

From historical time periods, the climate of this region was damp due to heavy rainfall in the monsoon season and temperature is rarely 
Table 1. Analysis of the test of significance.

\begin{tabular}{lcccc}
\hline Parameters & Test-statistic value & Threshold level & $p$-value & Accept/reject/no change \\
\hline Temperature $\left({ }^{\circ} \mathrm{C}\right)$ & 6.64 & 1.96 & $<0.001$ & Reject \\
Rainfall extreme $(\mathrm{mm})$ & 4.32 & 1.96 & $<0.001$ & Reject \\
\hline
\end{tabular}

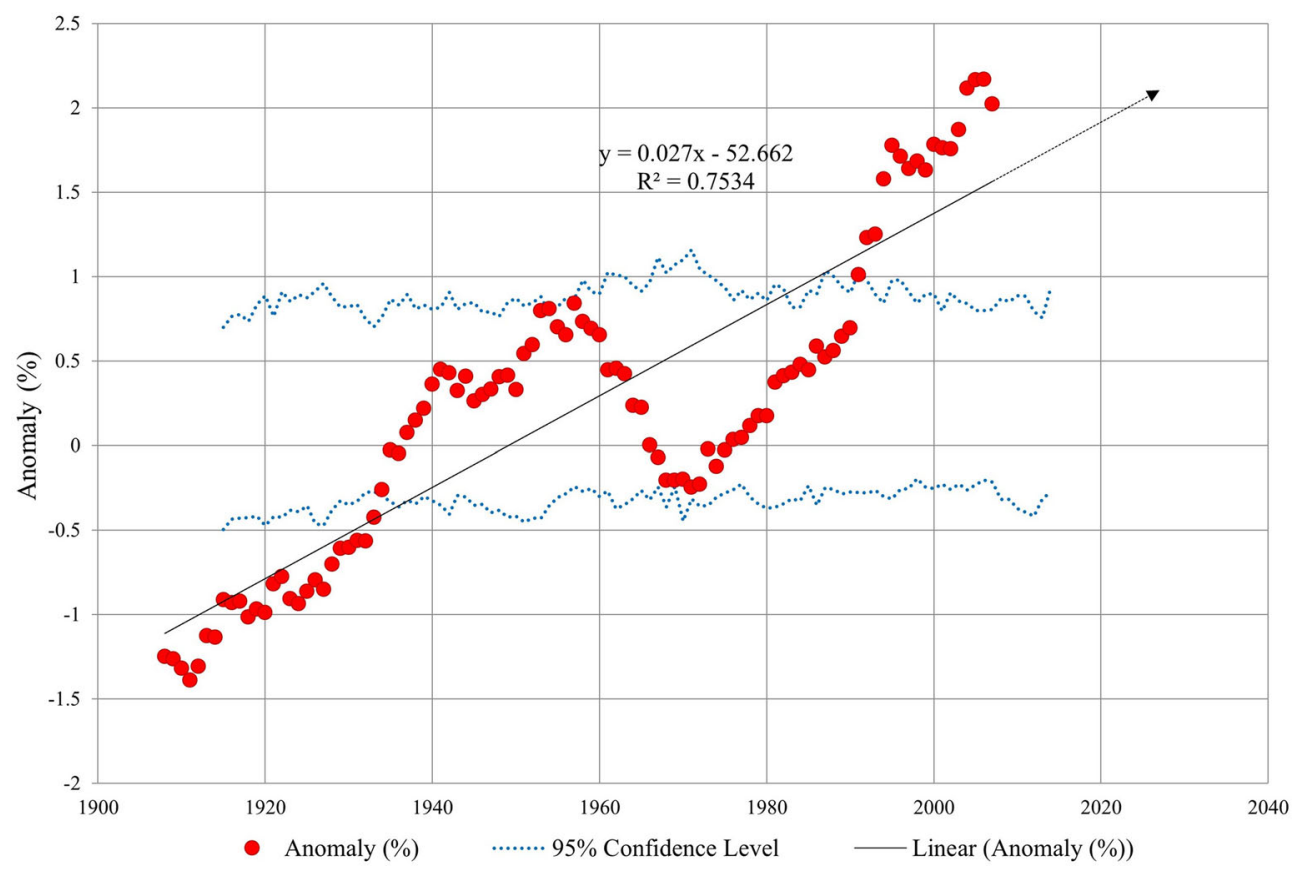

Figure 3. Anomalies in annual temperature based on full 114 years' length (1901-2014) using 15 years moving average.

excessive. But if we look at the multi-decadal trends of average annual temperature, from 1990 onwards the temperature is increasing and goes beyond the normal persistence (see figure 3). Anomalies in the average temperature increased around $1.5-2 \%$ (around $0.05^{\circ} \mathrm{C}$ year ${ }^{-1}$ ) from the 1990 s onwards and $R^{2}$ value (see figure 3 ) signifies the linear positive trend. On the other hand, lower extremes are found from 1910 to 1920 by considering more than 100 years of historical series. However, as this region is prone to floods and high extreme precipitation is generally observed during the monsoon season (June-August), the annual extreme rainfall is taken into consideration in the multi-decadal oscillations analysis. Figure 4(a and b) illustrates the trends of anomalies in extreme rainfall events of the Bengal Duars through 15 and 30 years of moving average. Multidecadal oscillations with higher rainfall quantiles for 1930-1940s and 1980s onwards and lower quantiles in 1960-1970 are observed. From this trend, the extreme events are fluctuating in an oscillating manner, and after the 1970s, trends of extreme events are not similar as approximate cyclic variations. Extreme precipitation quartiles are found to be around 5\% higher than the previous cluster periods of the past decades, and the oscillation altitude increased as an effect of climate change on rainfall extremes. The resultant recent cluster of heavy rainfall might be attributed to anthropogenic-induced climate change, given that the change in sign and order of magnitude is consistent with the global warming impact predictions following the regional climate model (IPCC 2007a, b; Lenderink et al. 2007; Min et al. 2011; Willems et al. 2012). Moreover, the analysis of this attribute needs further research for better understanding of the phenomenon.

\subsection{Variability in the seasonal climate of the Duars region}

The climatic variation on our planet can be described with a roughly bell-shaped curve, where the normal weather is very common while the extreme weather is rare. A small increase in temperature shifts the entire curve towards hotter high temperatures (see figure 5a). Widespread seasonal 

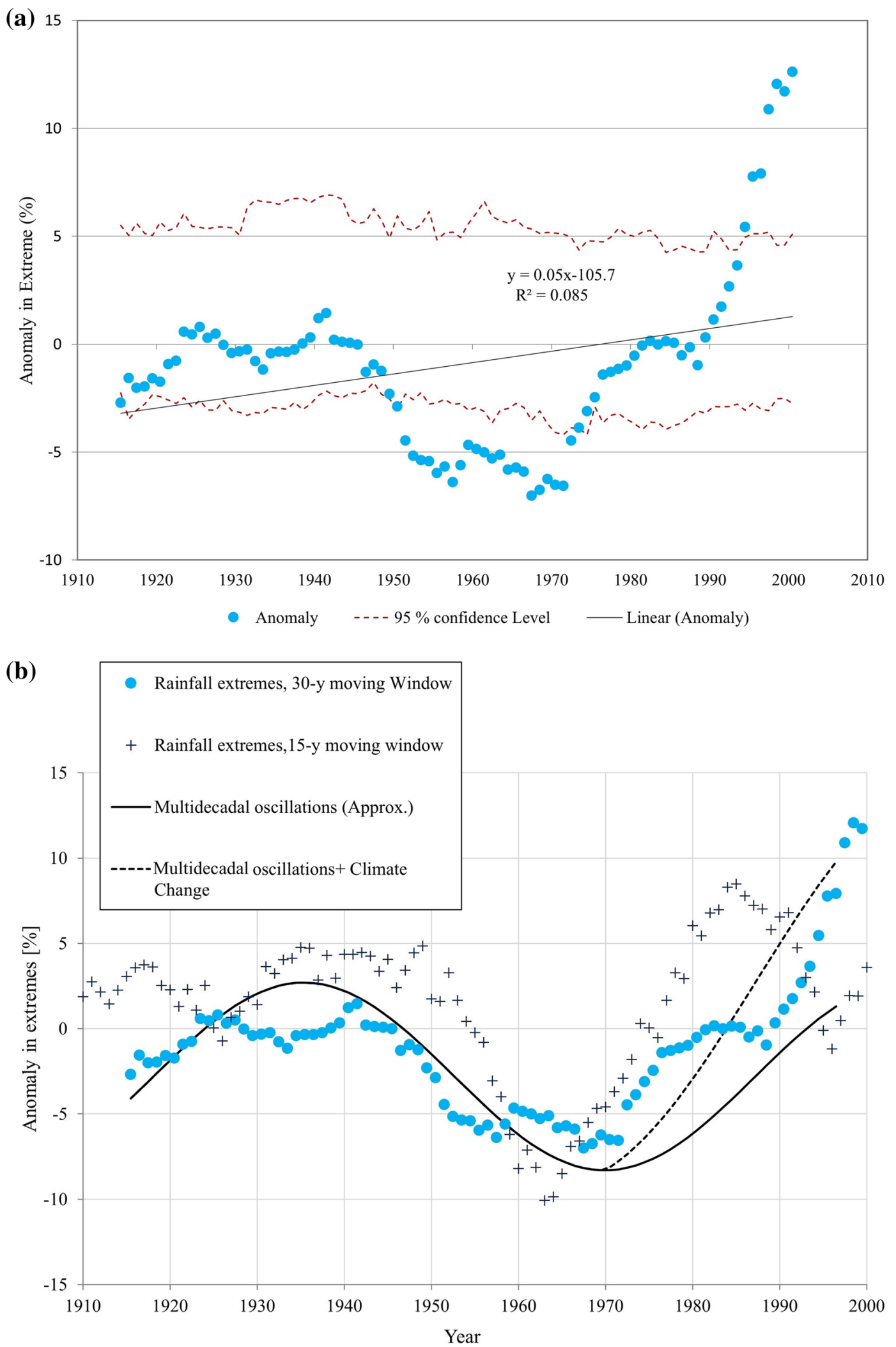

Figure 4. (a) Anomalies in annual rainfall extremes based on full 115 years' length from 1901 using 30 years moving average. (b) The identical change observed 1970's onward in rainfall extremes.

warming trends from the early 20th century to the present can also be seen in figure 4, shifting of monthly average temperature towards warm seasons (April-May) and warm periods also increased its length and frequency in the last 30 years. This region has experienced heavy rainfall 


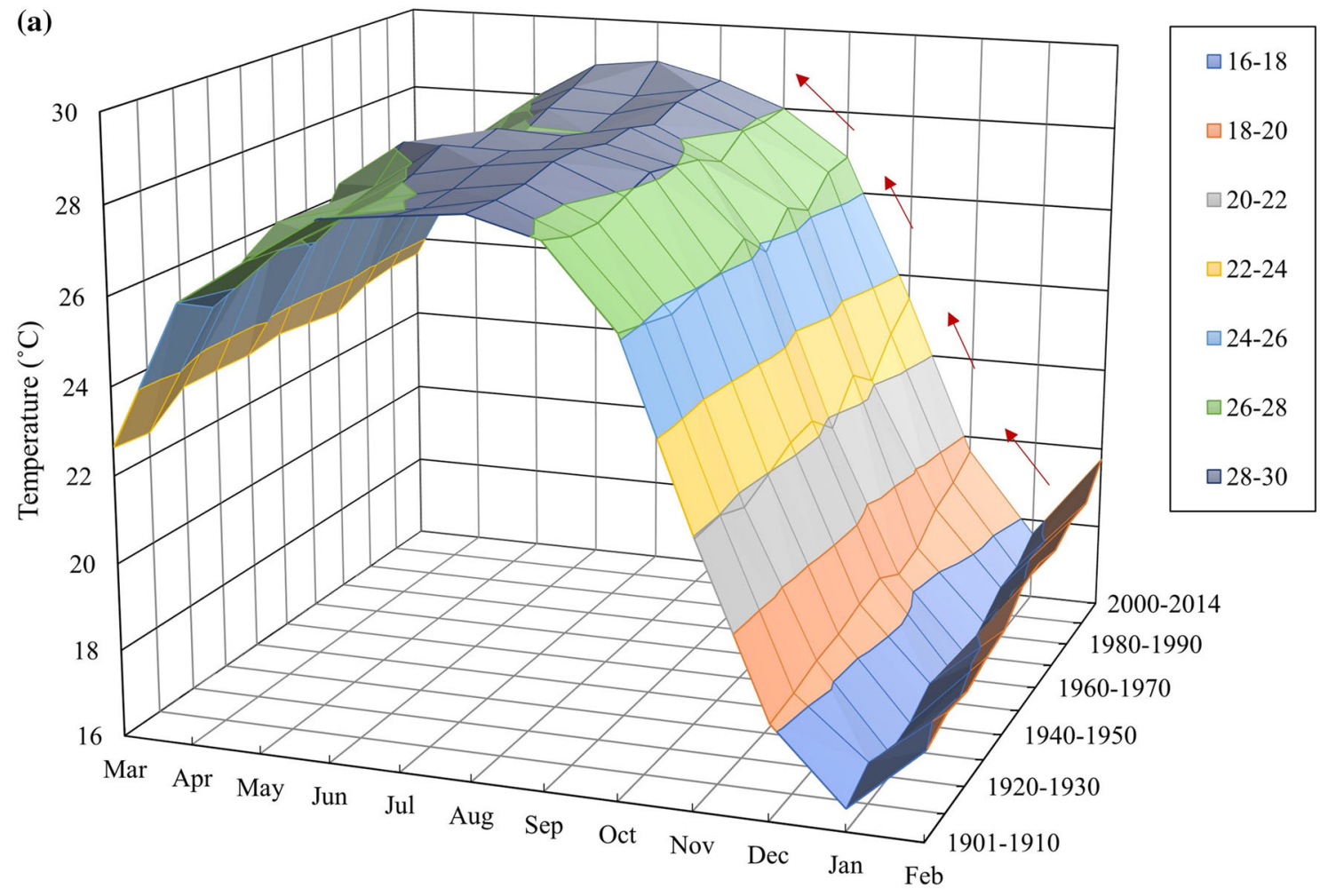

(b)

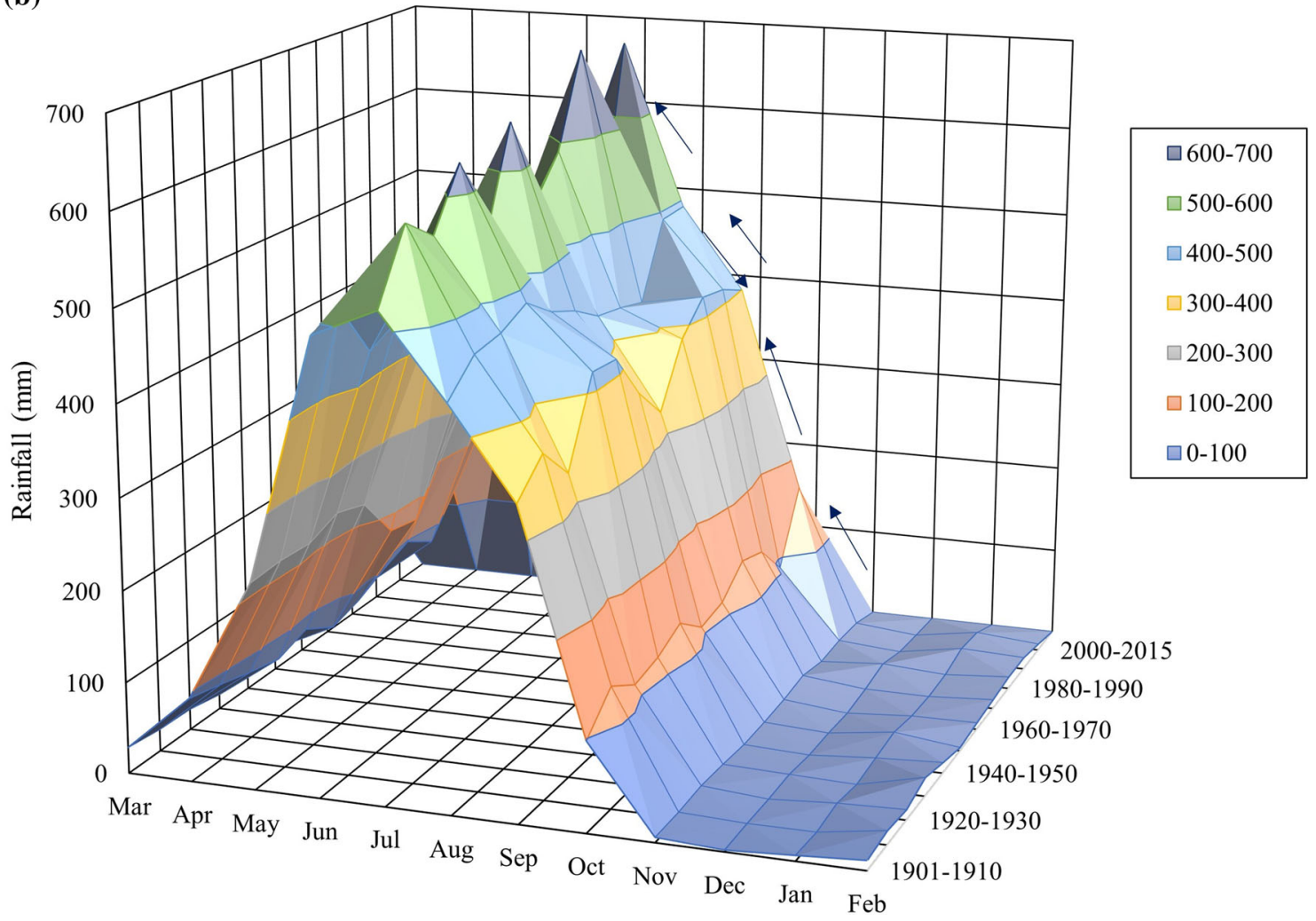

Figure 5. (a) Seasonal shifting of temperature towards summer seasons (April-June) and (b) the dichotomous trend of rainfall present in some months during the monsoon season (June-September).

during the monsoon season. Due to the increase of extreme rainfall events, the amount of monsoon rainfall has increased over the last two decades, but dichotomy is present in some months of the monsoon period (see figures $5 \mathrm{~b}$ and $6 \mathrm{~b}$ ). Instead of a day-to-day change in the weather, 


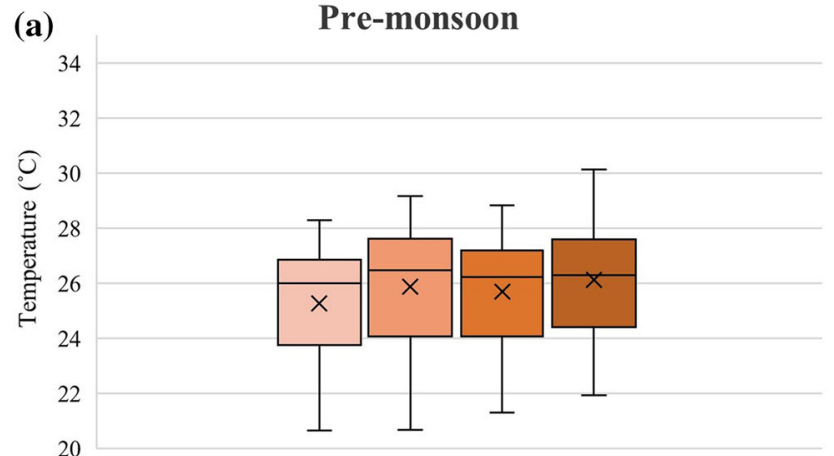

$\square$ 1901-1931 $\square$ 1931-1961 $\square$ 1961-1991 $\square$ 1991-2014

\section{Post-monsoon}

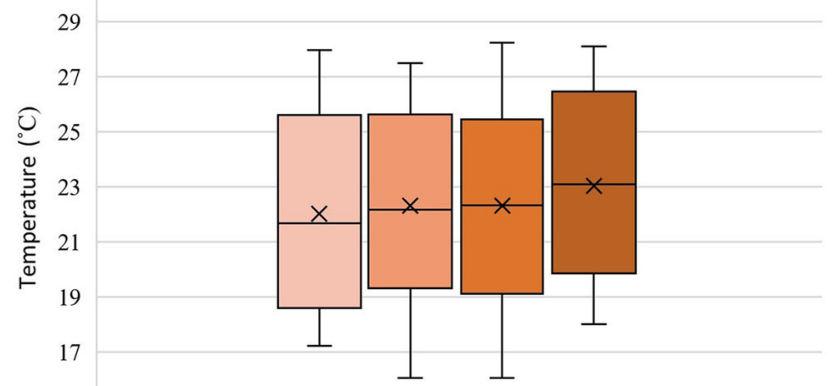

15

$\square$ 1901-1931 $\square$ 1931-1961 $\square$ 1961-1991 $\square$ 1991-2014

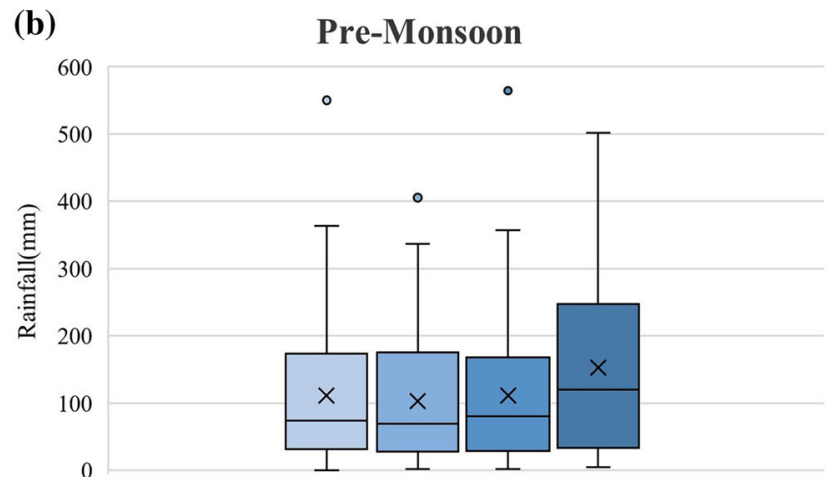

$\square$ 1901-1931 $\square$ 1931-1961 $\square$ 1961-1991 $\square$ 1991-2015

\section{Post-Monsoon}

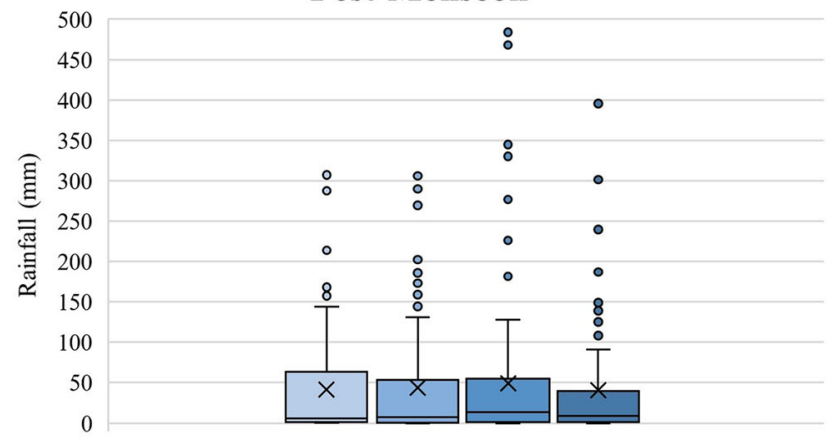

$\square$ 1901-1931 $\square$ 1931-1961 $\square$ 1961-1991 $\square$ 1991-2015

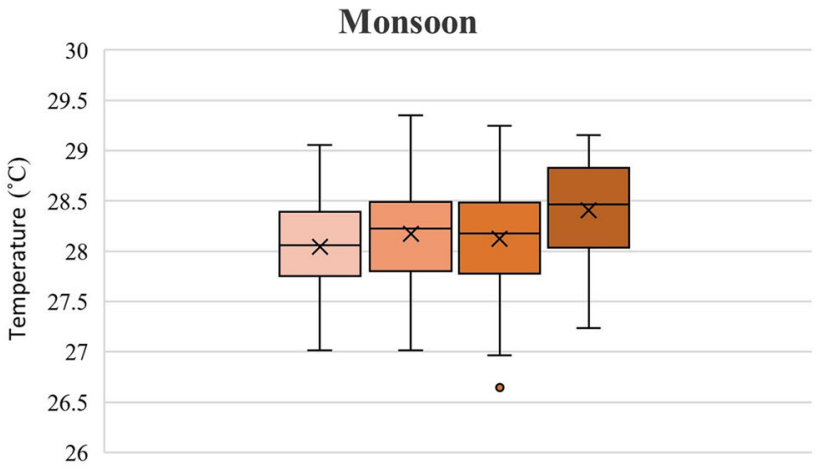

$\square$ 1901-1931 $\square$ 1931-1961 $\square$ 1961-1991 $\square$ 1991-2014

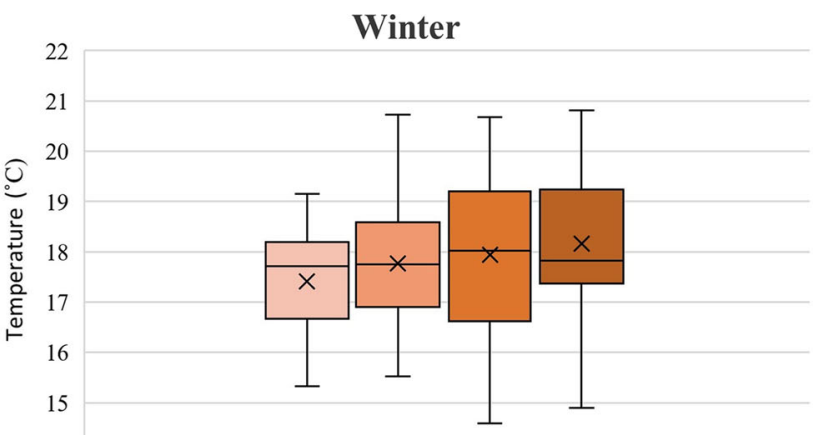

$\square$ 1901-1931 $\square$ 1931-1961 $\square$ 1961-1991 $\square$ 1991-2014

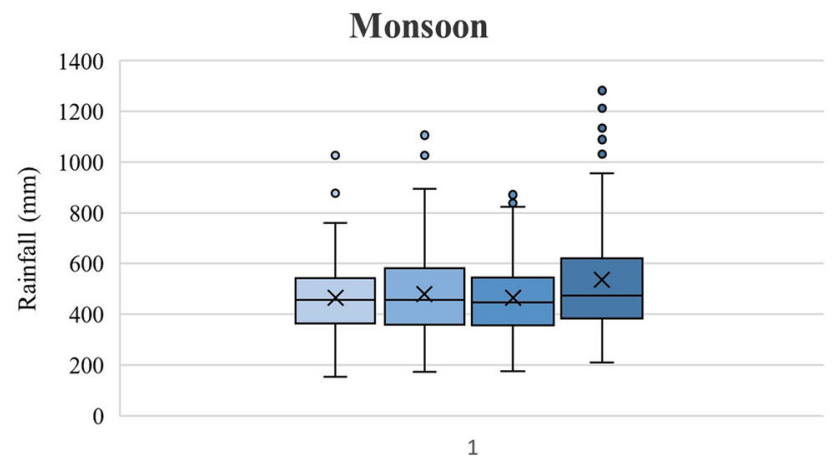

$\square$ 1901-1931 $\square$ 1931-1961 $\square$ 1961-1991 $\square$ 1991-2015

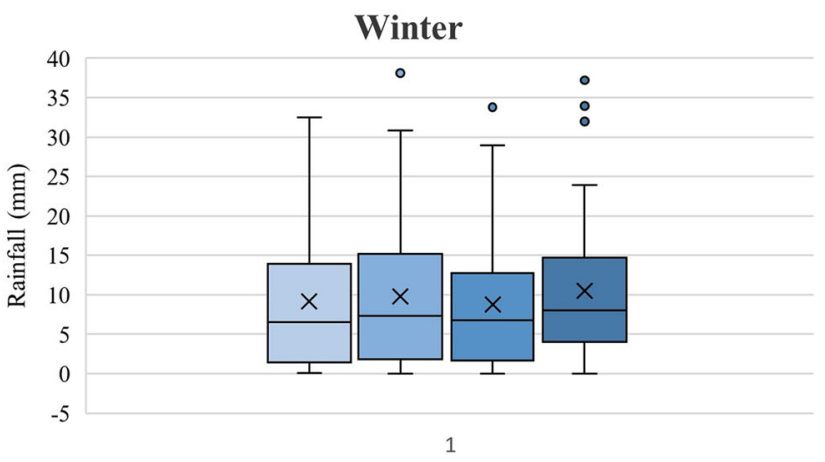

$\square$ 1901-1931 $\square$ 1931-1961 $\square$ 1961-1991 $\square$ 1991-2015

Figure 6. Dispersion and seasonal trends of (a) temperature and (b) rainfall. 
the climate varies over seasons and years. Due to the variations in the Sun's radiation over the Earth, inter-seasonal variation is quite common, but for a long period of time, variability in intra-seasonal climate has been very important in climatological research. For example, historical records of extreme rainfall events are used to calculate the probability of future rain events. We use long-term averages to make a societal decision. The production of crops, forest product and other natural resources can also vary in accordance with the shifting of seasonal climate (seasonal average). IMD has classified the Indian climate into four seasons such as pre-monsoon (March-May), monsoon (June-September), post-monsoon (OctoberDecember) and winter (January-February).

In this study, we also divide the seasonal climate of the Duars region into four major seasons by using IMD's scheme. The impact of global warming can also be seen in the regional climate as increasing trends of mean monthly average temperature in all the seasons (see figure 6a). The outliers present beyond the 1.5 times of inter-quartile ranges is an indication of an increase in extreme rain events especially during monsoon and post-monsoon periods. However, no significant trends are found for the winter season, but the amount of rainfall increases in pre-monsoon and monsoon seasons (see figure $6 \mathrm{~b})$.

\section{Discussion}

This study has attempted to analyse the trends of climatic variability at a regional landscape of Bengal Duars. India has experienced heterogeneous climatic variability in its different parts. Rajendran et al. (2013) analysed the significant increasing trend of summer monsoon rainfall over Northeast India including North Bengal by using present day IMD observations (1979-2007) and also portray different variability of rainfall patterns with diverse resolution models. However, the decreasing trend of summer monsoon rainfall over Northeast India (1970-2014) is addressed by Preethi et al. (2017). Raha et al. (2014) have observed the increasing trend of mean minimum temperature during the winter season and frequency of the number of rainy days increased significantly over Jalpaiguri district (1979-2008). Basak (2014) made a study on the variability of southwest monsoon in West Bengal and found that rainfall series of Alipurduar, Jalpaiguri and Kalchini exhibited a positive trend at $5 \%$ level of significance. The extreme rainfall events over Northeast India are found to be most abundant especially through the course of monsoon period during 1951-2007 (Srivastava et al. 2016). The present study explores linear as well as oscillating trends of temperature and rainfall extremes. The increasing trend in annual average temperature and rainfall extreme are observed. The dichotomous variability present within the monsoon period of the Bengal Duars has explored. This region also experienced a positive trend of temperature in all the seasons and the amount of rainfall increased in recent decades especially during the pre-monsoon and monsoon periods. All together causes intra-seasonal climatic variability throughout the year. As this region covers a large percentage of forest assemblage, these changes can affect the timing of many life cycle events which will have further impact on the livelihoods of local people who are dependent on forest resources. Above all, different species may respond to different environmental cues, which may have an adverse effect on whole ecosystems.

\section{Conclusions}

There is a conformity in the results obtained from the Mann-Kendall test as well as in the linear trend line of the Duars region. On the basis of the aforesaid technique for the recognition and analysis of changes in extremes, there is an increasing trend in rainfall extremes followed by an oscillatory behaviour at multi-decadal time scales. Moreover, the recent upward trend of extremes is found to be at the positive phase of this oscillation. Therefore, it is expected that rainfall extreme will be $5 \%$ higher than the normal trend. Even a decreasing trend (after few decades) might have been initiated in the region, but considering the recent amplitude of change, this decreasing nature will not be as similar as in the 1960s. Increasing trends of temperature have been found to be statistically significant (at 95\% confidence interval) at the rate of $0.027^{\circ} \mathrm{C}^{-1}$. Therefore, it may be inferred that temperature will increase at a rate of $0.2^{\circ} \mathrm{C}$ or more in the next decades. On the other hand, seasonal shifting of temperature may cause disappearing of micro-seasons such as spring, autumn, etc., due to overlapping of main seasons. 


\section{Acknowledgements}

The authors would like to acknowledge the University Grants Commission, New Delhi, India, for the financial support as Junior Research Fellowship (Award Letter No. 3108/(NET-JUNE 2014)) to carry out the research work presented in this paper. We would also like to acknowledge IMD, Pune, India, for providing the climatic dataset. We are grateful to the anonymous reviewers for their valuable comments during the preparation of the present work.

\section{References}

Allison I, Bindoff N, Bindschadler R, Cox P, NobletDucoudré N de, England M, Francis J, Gruber N, Haywood A, Karoly D, Kaser G, Le Quéré C, Lenton T, Mann M, McNeil B, Pitman A, Rahmstorf S, Rignot E, Schellnhuber H J, Schneider S, Sherwood S, Somerville R, Steffen K, Steig E, Visbeck M and Weaver A 2009 The Copenhagen diagnosis: Updating the world on the latest climate science; UNSW Climate Change Research Centre, Sydney, Australia (http://www.giss. nasa.gov/research/news/20100121/).

Basak P 2014 Variability of south-west monsoon rainfall in West Bengal: An application of principal component analysis; Mausam 65(4) 559-568.

Dessai S and Hulme M 2001 Climatic implication of revised IPCC emission scenarios, the Kyoto Protocol and quantification of uncertainties; Integr. Assess. 2(3) 159-170.

Gruning J F 1911 Eastern Bengal and Assam district gazetteers; WBDG, Govt. of West Bengal, Jalpaiguri.

Hamilton F B 1838 The history, antiquities topography and statistics of Eastern India comprising the districts of Puraniya, Ronggopoor and Assam; Collated from the Original Documents (i.e., from F Buchanan's Accounts of these districts $1807-1814$ by Montgomery Martin), vol. 3, London.

IPCC (Climate Change) 2007a Synthesis report; In: Contribution of working groups I, II and III to the fourth assessment report of the intergovernmental panel on climate change (eds) Core Writing Team, Pachauri RK and Reisinger A, Geneva, Switzerland, pp. 30-33.

IPCC (Climate Change) 2007b The physical science basis; Cambridge University Press, Cambridge and New York.

IPCC (Climate Change) 2014 Synthesis report; In: Contribution of working groups I, II and III to the fifth assessment report of the intergovernmental panel on climate change (eds) Core Writing Team, Pachauri R K and Meyer LA, Geneva, Switzerland, pp. 56-62.

Jana M M 2002 Management and development of river basins in North Bengal using remote sensing techniques; Photonirvachak; J. Indian Soc. Remote Sens. 25(2) 105-111.

Karan P P 1966 Geographic regions of the Himalaya; Bull. Tibetol. 3(2) 5-27.

Kaur S, Diwakar S K and Das A K 2017 Long term rainfall trend over meteorological subdivisions and districts of India; Mausam 68(3) 439-450.
Laskar S I, Kotal S D and Roy Bhowmik S K 2014 Analysis of rainfall and temperature trends of selected stations over North East India during last century; Mausam 65(4) 497508.

Lenderink G, van Ulden A, van den Hurk B and Keller F 2007 A study on combining global and regional climate model results for generating climate scenarios of temperature and precipitation for the Netherlands; Clim. Dyn. 29(2) 157-176.

Min S K, Zhang X, Zwiers F W and Hegerl G C 2011 Human contribution to more intense precipitation extremes; Nature 470 378-381.

Nicholson S E, Some B and Kone B 2000 An analysis of recent rainfall conditions in west Africa, including the rainy seasons of the $1997 \mathrm{El} \mathrm{Nino} \mathrm{and} \mathrm{the} 1998 \mathrm{La}$ Nina years; J. Clim. 13(14) 2628-2640.

Ntegeka V and Willems P 2008 Trends and multidecadal oscillations in rainfall extremes, based on a more than 100 years' time series of 10 minutes' rainfall intensities at Uccle, Belgium; Water Resour. Res. 44 115.

Peterson T C and Baringer MO 2009 State of the climate in 2008; Bull. Am. Meteorol. Soc. 90(8) S1-S198, http:// www.giss.nasa.gov/research/news/20160120/.

Pittock A B 2009 The science impact and solutions; CSIRO Publishing, Australia.

Preethi B, Mujumdar M, Kripalani R H, Prabhu A and Krishnan R 2017 Recent trends and tele-connections among South and East Asian summer monsoons in a warming environment; Clim. Dyn. 48 2489-2505, https:// doi.org/10.1007/s00382-016-3218-0.

Radhakrishnan K, Sivaraman I, Sunil Kumar Jena S K, Sarkar S and Adhikari S 2017 A climate trend analysis of temperature and rainfall in India; Clim. Change Environ. Sustain. 5(2) 146-153.

Raha G N, Bhattacharjee K, Das M, Dutta M and Bandyopadhyay S 2014 Statistical study of surface temperature and rainfall over four stations in north Bengal; Mausam 65(2) 179-184.

Rajeevan M, Joyti B and Jaswal A K 2008 Analysis of variability and trends of extreme rainfall events over India using 104 years of gridded daily rainfall data; Geophys. Res. Lett. 35 L18707, https://doi.org/10.1029/ 2008GL035.

Rajendran K, Sajani S, Jayasankar C B and Kitoh A 2013 How dependent is climate change projection of Indian summer monsoon rainfall and extreme events on model resolution? Curr. Sci. 1041409 1418.

Rakhecha P R and Pisharoty P R 1996 Heavy rainfall during monsoon season: Point and spatial distribution; Curr. Sci. 71(3) 179-186.

Ravindranath N H, Rao S, Sharma N, Nair M, Gopalakrishnan R, Rao S A, Malaviya S, Tiwari R, Sagadevan A, Munsi M, Krishna N and Bala G 2011 Climate change vulnerability profiles for North East India; Curr. Sci. 101(3) 384-394.

Rennie S 1866 Bhutan and the story of the Dooars war; J. Murray, London.

Sen Roy S and Singh R B 2002 Climate variability, extreme events and agriculture productivity in mountain regions; Oxford and IBH Publication, New Delhi. 
Sinha Ray K C and Srivastava A K 2000 Is there any change in extreme events like heavy rainfall? Curr. Sci. 79(2) $155-158$

Somorin A O 2010 Climate impacts, forest-dependent rural livelihoods and adaptation strategies in Africa: A review; Afr. J. Environ. Sci. Technol. 4(13) 903-912.

Srivastava A K, Singh G P and Singh O P 2016 Variability and trends in extreme rainfall over India; Mausam 67(4) 745-766.

Turner A G, and Slingo J M 2009 Uncertainties in future projections of extreme precipitation in the Indian monsoon region; Atmos. Sci. Lett. 10 152-158.

West Bengal District Gazetteers 1981 Govt. of West Bengal, Calcutta, Jalpaiguri.

Corresponding editor: A K SAHAI
Willems P 2013a Multidecadal oscillatory behaviour of rainfall extremes in Europe; Clim. Change 120 931944.

Willems P 2013b Revision of urban drainage design rules after assessment of climate change impacts on precipitation extremes at Uccle, Belgium; J. Hydrol. 496 166177.

Willems P, Olsson J, Arnbjerg-Nielsen K, Beecham S, Pathirana A, Bülow Gregersen I, Madsen H and Nguyen VT-V 2012 Practices and impacts of climate change on rainfall extremes and urban drainage; IWA Publishing.

World Meteorological Organization 1996 Some methods of climatological analysis; Technical Note No. 81, WMO-No. 199, TP.103, Geneva, Switzerland. 